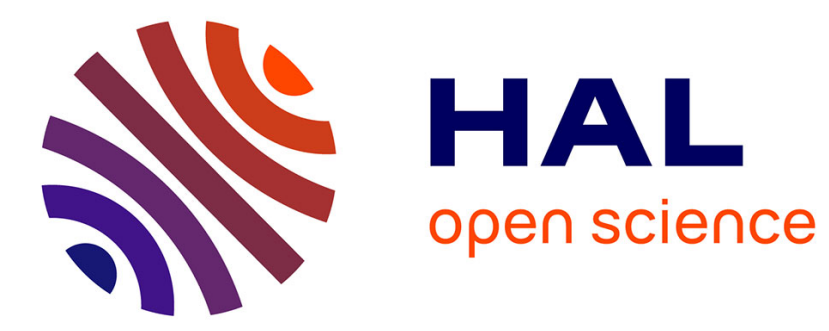

\title{
Plasma Spraying of Magnetite Coatings for M.W. Applications
}

\author{
R. Enikov, I. Nedkov, D. Oliver
}

\section{To cite this version:}

R. Enikov, I. Nedkov, D. Oliver. Plasma Spraying of Magnetite Coatings for M.W. Applications. Journal de Physique IV Proceedings, 1997, 07 (C1), pp.C1-603-C1-604. 10.1051/jp4:19971249 jpa00254935

\section{HAL Id: jpa-00254935 https://hal.science/jpa-00254935}

Submitted on 1 Jan 1997

HAL is a multi-disciplinary open access archive for the deposit and dissemination of scientific research documents, whether they are published or not. The documents may come from teaching and research institutions in France or abroad, or from public or private research centers.
L'archive ouverte pluridisciplinaire HAL, est destinée au dépôt et à la diffusion de documents scientifiques de niveau recherche, publiés ou non, émanant des établissements d'enseignement et de recherche français ou étrangers, des laboratoires publics ou privés. 


\title{
Plasma Spraying of Magnetite Coatings for M.W. Applications
}

\author{
R. Enikov, I. Nedkov and D. Oliver \\ Institute of Electronics, Bulgarian Academy of Sciences, 72, Tzarigradsko Chaussee blvd. Sofia 1784, \\ Bulgaria
}

Abstract. The possibilities of arc - plasma spray deposition of polycrystalline ferromagnetic coating are investigated. Powder sintered microwave absorbing ferrite materials were deposited by arc-plasma jet on polycrystalline substrates. By varying the distance between plasma torch and substrates and the spray duration, coatings with different thickness and porosity were obtained. The coatings characteristics were studied by optical, SEM and XRD methods. The mechanism of the magnetic structure formation was controlled by Mössbauer spectroscopy. The microwave absorption at $9.4 \mathrm{GHz}$, measured using a standard waveguide equipment was found to be $26 \%$.

1. Introduction. The increasing interest towards planar ferrite structures as media for passive microwave devicto i1] stimulates the development of various methods for ferrite coatings deposition. Basic requirements are: high deposition rate, control of composition and crystal phase. In this work the method of arc-plasma spray deposition (APS) is investigated. The aim of the research is to obtain magnetite $\mathrm{Fe}_{3} \mathrm{O}_{4}$ coatings. Magnetite has a structure of a inverse spinel with a general formula $\mathrm{Fe}^{3+}\left[\mathrm{Fe}^{2+} \mathrm{Fe}^{3+}\right] \mathrm{O}_{4}$. It is a traditional material for absorbing microwave coatings [2]. Magnetite is a test material for the technique developed since the conditions in the plasma jet (high temperature and oxidation-reduction processes) could lead to differences between the starting material and the coating with respect to phase and chemical composition.

2. Experiments. The APS method is used for obtaining comparatively thick coatings - from tens of microns to several millimetres. The plasma torch generates a jet with a temperature up to $10000 \mathrm{~K}$, velocity - hundred $\mathrm{m} / \mathrm{s}$, gas enthalpy - 10 $15 \mathrm{MJ} / \mathrm{kg}$. The sprayed material in form of powder is injected in the jet. The powder particle size is usually tens of microns. In the plasma jet, the particles are accelerated, heated and molten. They are collected on the substrate, set at a fixed distance from the torch. There they cool off and recrystallise $[3,4]$. The diffusion of material from coating to substrate is minimal. In fig. 1. the experimental set-up is presented. A DC plasma torch is used. The plasma arc is gas vortex and magnetically stabilised and operates at atmospheric pressure. The plasma temperature is measured using the method of light emission spectroscopy. The nozzle design (with an operating diameter of $6 \mathrm{~mm}$ ) provides radial temperature gradient smaller than in the conventional cases. Thus the powder particles passing through the jet to the substrate do not differ substantially in velocity and temperature. As a result, the quality of the coating improves. Air is used as plasma gas to decrease the chemical reduction of $\mathrm{Fe}_{3} \mathrm{O}_{4}$ in the plasma. High purity $\mathrm{Fe}_{3} \mathrm{O}_{4}$ is used with traces of $\mathrm{FeO}$ about $1 \%$ wt. The size of the ferrite powder particles in the different experiments varies within $3-40 \mu \mathrm{m}$. They are injected into the nozzle by the carrier gas $\mathrm{Ar}$. The substrate is a plate of polycrystalline $\mathrm{Al}_{2} \mathrm{O}_{3}$. Typical parameters of the process are: electric power $20-40 \mathrm{~kW}$, plasma gas rate $1-2 \mathrm{~g} / \mathrm{s}$, powder feed rate $0.5-2 \mathrm{~g} / \mathrm{s}$, torch-to-base distance $9-15 \mathrm{~cm}$. The deposition rate is $0.15 \mathrm{~mm} / \mathrm{s}$. The coating thickness is obtained by single or repeated exposure in the jet,

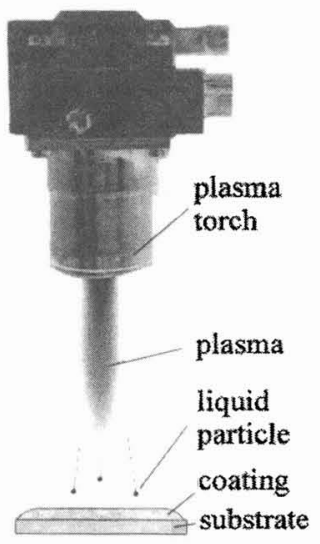

Fig. 1. Experimental set-up 

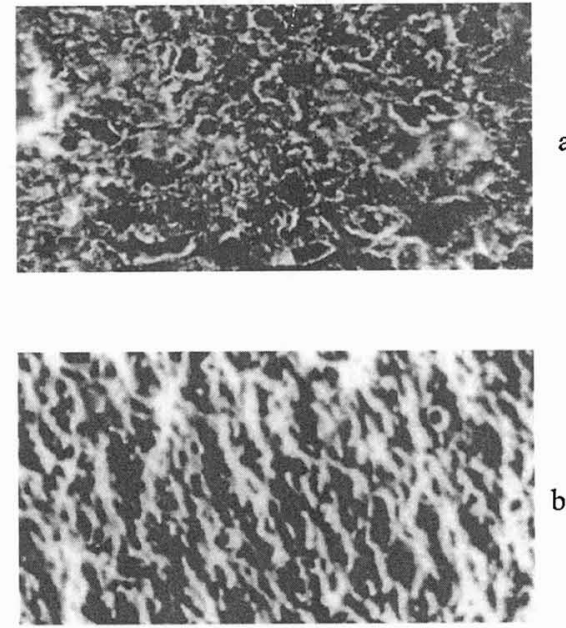

Fig. 2. a-coating cross-section optical photography $\mathrm{b}$ - SEM of a coating surface

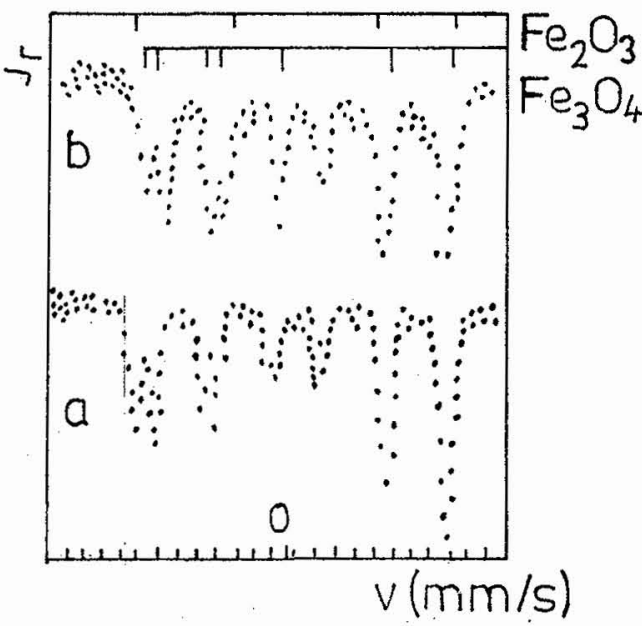

Fig. 3. Mössbauer spectrum: a $-\mathrm{Fe}_{2} \mathrm{O}_{3}-24 \%$; b $-\mathrm{Fe}_{2} \mathrm{O}_{3}-7 \%$

3. Results. The coatings obtained are 50-200 $\mu \mathrm{m}$ thick. Fig $2 \mathrm{a}$ is a photograph of a coating cross-section in which the grainlayer structure, typical for the APS method can be observed. The porosity is $6-15 \%$ and depends on the operating mode, the particle size, and the torch-to-substrate distance. The particles molten in the jet cool off and recrystallize on the substrate. Some undesired for the m.w. coating application processes can take place: 1 . When cooling is fast the oxide can remain in amorphous phase; 2 . Reduction processes can take place in the heated particles in the jet or on the substrate; as a result lower oxides appear. The experiment shows that when the process parameters are optimised, coatings with crystalline structure are obtained. This is confirmed by the XRD analyses. In fig. $2 b$ a coating surface SEM is shown, which again confirms its polycrystalline composition. XRD as well as Mössbauer spectroscopy (fig.3) proves the presence of a second component. It is $\mathrm{Fe}_{2} \mathrm{O}_{3}$ in $\gamma$-phase. $\mathrm{Fe}_{2} \mathrm{O}_{3}$ has a cubical crystalline spinel lattice and is described with a general formula $\mathrm{Fe}^{3+}{ }_{8}\left[\left(\mathrm{Fe}^{3+}{ }_{13}\right)_{13}\left(\square_{2}\right)_{2 B}\right] \mathrm{O}^{2-}{ }_{32}$, where $\square$ are cationic vacancies. The fractional amount of vacancies and ions in the octoedric sublattice is an additional prerequisite for implanting $\mathrm{Fe}^{3+}$ which obstructs the obtaining of good absorption coatings. When optimising the operating mode the concentration of $\mathrm{Fe}_{2} \mathrm{O}_{3}$ is decreased to under 7\% (fig.3b). Both XRD and Mössbauer methods do not detect any presence of $\mathrm{FeO}$ in the coating. In the Mösbauer spectral lines, the typical for the $\mathrm{FeO}$ quadrupole split is not recorded.

It is known that after subsequent thermal treatment of the coating in oxygen atmosphere the lower oxides disappear. Our purpose is to avoid this additional treatment, which brings about some specific requirements for the substrate material [3]. The microwave absorption at $9.4 \mathrm{GHz}$ is determined by measuring USWR and attenuation using a standard waveguide equipment. The samples are placed at the maximum of the electric field. The reflected, transmitted and absorbed components of the microwave power are measured. For the samples with $7 \% \mathrm{Fe}_{2} \mathrm{O}_{3}$ impurities the measured $\mathrm{MW}$ energy absorption was maximum (about $26 \%$ ).

4. Conclusion. The proposed APS method allows obtaining of ferrite coatings with preset thickness, porosity and phase composition at a minimal presence of lower oxides.

Work was sponsored by the National Faund of Scientific Research, Bulgaria, under Grant No F - 639.

\section{Reference}

1. A. Fathi, D.Kalokitis, V.Pendtick. IEEE, MTTS (1993), 1997.

2. I Nedkov, L. Milenova, N. Dichovski. IEEE, Trans. Mag. 6, (1994), 2045.

3. D.H.Harris, R.J.Janovski. J. of Appl. Phys., 41', 3, (1970), 1348.

4. T.Konaka, I.Sankava. Jap. J. of Appl. Phys. 27, 6, (1988), 1092. 